\title{
Hydroxyapatite extracted from Waste Fish Bones and Scales via Calcination Method
}

\author{
N.Mustafa. ${ }^{1, a}$, M.H.I Ibrahim ${ }^{2, b}$, R.Asmawi ${ }^{3, c}$, A.M.Amin ${ }^{4, d}$ \\ ${ }^{1}$ Faculty of Mechanical and Manufacturing Engineering \\ Universiti Tun Hussein Onn Malaysia
}

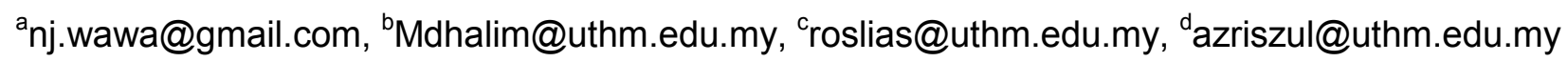

Keywords: Hydroxyapatites, Natural Sources, Calcination Method

\begin{abstract}
A hydroxyapatite is known as one of vital materials and common use in biomedical field and concentrated in clinical area. In relation to the above, the development of hydroxyapatite powder becomes an attractive research lines due to simplify in produce it. Thus in this paper the researcher stress out about Hydroxyapatite powder gained from the natural sources or so called as the waste of Tilapia bone and scales. The raw bones of and scale were undergo to crushing process to form in powder size $(0.2 \mathrm{~mm})$ then analysed by X-ray Diffraction (XRD) to identified the mineralogy of raw bone. Moreover the powder of fish bone and scales also go through to Scanning Electron Microscope (SEM) machine to analyse the microstructure of the powder while EDS act as device to determine the chemical composition of the sample powder. Sample powder then forward calcination process at selected temperature range to as a cheaper method in obtained hydroxyapatite raw sources. The range of calcination temperatures are between $800^{\circ} \mathrm{C}$ to $1000{ }^{\circ} \mathrm{C}$. The sample preparation were analysed in both condition before and after calcination process by using XRD, SEM and EDS. The HAP crystalline composition of tilapia bones for raw powder and at $800{ }^{\circ} \mathrm{C}$ are similar with HAP pattern (JDS 00-009-0432) and the chemical reaction is $\mathrm{Ca}_{5}(\mathrm{PO} 4)_{3}(\mathrm{OH})$ then at temperature 900 and 1000 similar to HAP pattern (JDS 00-055-0592) with chemical reaction equal to $\mathrm{Ca}_{10}(\mathrm{PO} 4)_{6}(\mathrm{OH})_{2}$.
\end{abstract}

\section{Introduction}

Nowadays, Medical implant technology developments are classified as the important aspect in term of biomedical application and the most is in clinical field. The aims in modern medical technology are focused on toward higher availability and more flexibility. There are a few conventional method in bone treatment process such as polymethylmethacrylate (PMMA) bone cement, calcium phosphate cement (CPC), and glass based bone cement (GBC). Therefore the implement of hydroxyapatite was selected as the vital operation process in bone treatment compared to conventional method [1]. Hydroxyapatite (HAP) is one of constituent that had found in either in human bone or teeth and the major elements are including calcium and phosphorous. HAP is more stable if the ratio is closer to 1.67 and the lower this ratio the larger is the bioactivity. Other than that, the Reactivity depends on the degree of crystallinity [2]. Generally hydroxyapatite $\left(\mathrm{Ca}_{10}\right.$ $\left.\left(\mathrm{PO}_{4}\right)_{6}(\mathrm{OH})_{2}\right)$ consist in structure of bone where as similar to their natural mineral composites [3]. Regarding to their similarity, its make it suitable to apply as an implant materials in dental and orthopaedic field. Basically, hydroxyapatite is revealed either from the bone or obtains from the direct precipitation of calcium and phosphate ions. Hydroxyapatites that produce from natural resources are better their metabolic activity and more dynamic response to the environment compared to the synthetic process[4]. The problems of hydroxyapatite powder produced by synthetic process are needed additional chemical to improve the mechanical strength and many chemical involved in process to stable the structures and fixed in human body. This method is rather complicated and required high initial cost to produce HAP. Moreover the HAP from natural is cheaper and uncomplicated compared to synthetic method. Besides, this process also takes a long time and difficult to control the sample of hydroxyapatite produced [5].

Based on this problem, this paper aims to produced the hydroxyapatite powder from the natural sources (Tilapia scale and bone) followed by calcination method to analysis the hydroxyapatite structures 


\section{Methodology}

Sample Preparation. The sample preparation are begin with boiled the tilapia and fish scales in 2 hour duration in order to remove the adherent fish meat. Then, the bones and scales were dried at least two day in room temperature to make sure there the removal of the water and organic portion from boiled process are left behind. After that the crushing process were take place to reduce the size of scales or in other words to transform the scales into powder form in $0.2 \mathrm{~mm}$ of range size. Last step but not least, the raw powder of tilapia fish and scales then continue to calcination process.

Calcination Process. The hydroxyapatite powder was produce after the raw powder of tilapia and fish scales were posses a calcination stages. Calcination process is categorized as intelligent way in produce the hydroxyapatite powder due to low cost and uncomplicated method. The raw sample powders were heated in Protherm furnace in temperature range between $800^{\circ} \mathrm{C}$ to $1000{ }^{\circ} \mathrm{C}$ at a heating rate of $5{ }^{\circ} \mathrm{C} / \mathrm{min}$ in 5 hour. As soon as the calcination temperature had been reached, the sample will maintain cooled naturally in the furnace.

Sample Powder Characterization. The characterizations of sample powder either before or after calcination process were analyzed by Scanning Electron Microscope (SEM) machine to analyze the microstructure of the powder while EDS act as device to determine the chemical composition of the sample powder. X-ray Diffraction (XRD) to identify the mineralogy of sample powder and use to confirm the purity and stability phase of sample powder. The graph are based on relative intensity against $2 \theta$

\section{Results and Discussions}

General descriptions. The raw fish bone and scales powders were undergo to calcination process in order to produce the hydroxyapatite powder. The selected range of temperature are between $800^{\circ} \mathrm{C}$ to $1000{ }^{\circ} \mathrm{C}$ is due to calcination of raw bone at $600{ }^{\circ} \mathrm{C}$ to $900{ }^{\circ} \mathrm{C}$ led to the formation of pure HAP [5]. The raw fishbone powder are observed as yellow then turned into white color at $800^{\circ} \mathrm{C}$ and $900{ }^{\circ} \mathrm{C}$ then at $1000{ }^{\circ} \mathrm{C}$ turned out into soft blue. Therefore the isolation yield of the sample at $800{ }^{\circ} \mathrm{C}, 900{ }^{\circ} \mathrm{C}$ and $1000{ }^{\circ} \mathrm{C}$ is equal to $58.571 \%, 58.036 \%$ and $58.741 \%$.

Table 1: Description of Calcination Data

\begin{tabular}{|c|c|c|c|c|c|c|}
\hline $\begin{array}{c}\text { List of } \\
\text { Sample }\end{array}$ & $\begin{array}{c}\text { Calcination } \\
\text { Temperature } \\
\left({ }^{\circ} \mathrm{C}\right)\end{array}$ & $\begin{array}{c}\text { Calcination } \\
\text { Period }(\mathrm{h})\end{array}$ & $\begin{array}{c}\text { Initial } \\
\text { Weight }(\mathrm{g})\end{array}$ & $\begin{array}{c}\text { After } \\
\text { Calcination } \\
(\mathrm{g})\end{array}$ & $\begin{array}{c}\text { Residue } \\
(\%)\end{array}$ & $\begin{array}{c}\text { Descriptions } \\
(\text { Colour of } \\
\text { sample })\end{array}$ \\
\hline $\begin{array}{c}\text { Raw fish } \\
\text { Powder }\end{array}$ & - & - & - & - & - & Yellow \\
\hline 1 & 800 & 5 & 2.100 & 1.230 & 58.571 & White \\
\hline 2 & 900 & 5 & 2.016 & 1.170 & 58.036 & White \\
\hline 3 & 1000 & 5 & 2.002 & 1.176 & 58.741 & Soft Blue \\
\hline
\end{tabular}

Scanning Electron Microscope Analysis. Figure 1 below presented the morphology surface of raw fish bones powder and after calcination process at the range temperature between $800^{\circ} \mathrm{C}$ to $1000{ }^{\circ} \mathrm{C}$. It can be seen that the microstructure of raw powder particle (a) is small size and in spherical form compared to after calcination process. Meanwhile the particle size is more increased and crystallinity parallel with the increment of calcination temperature [6] 


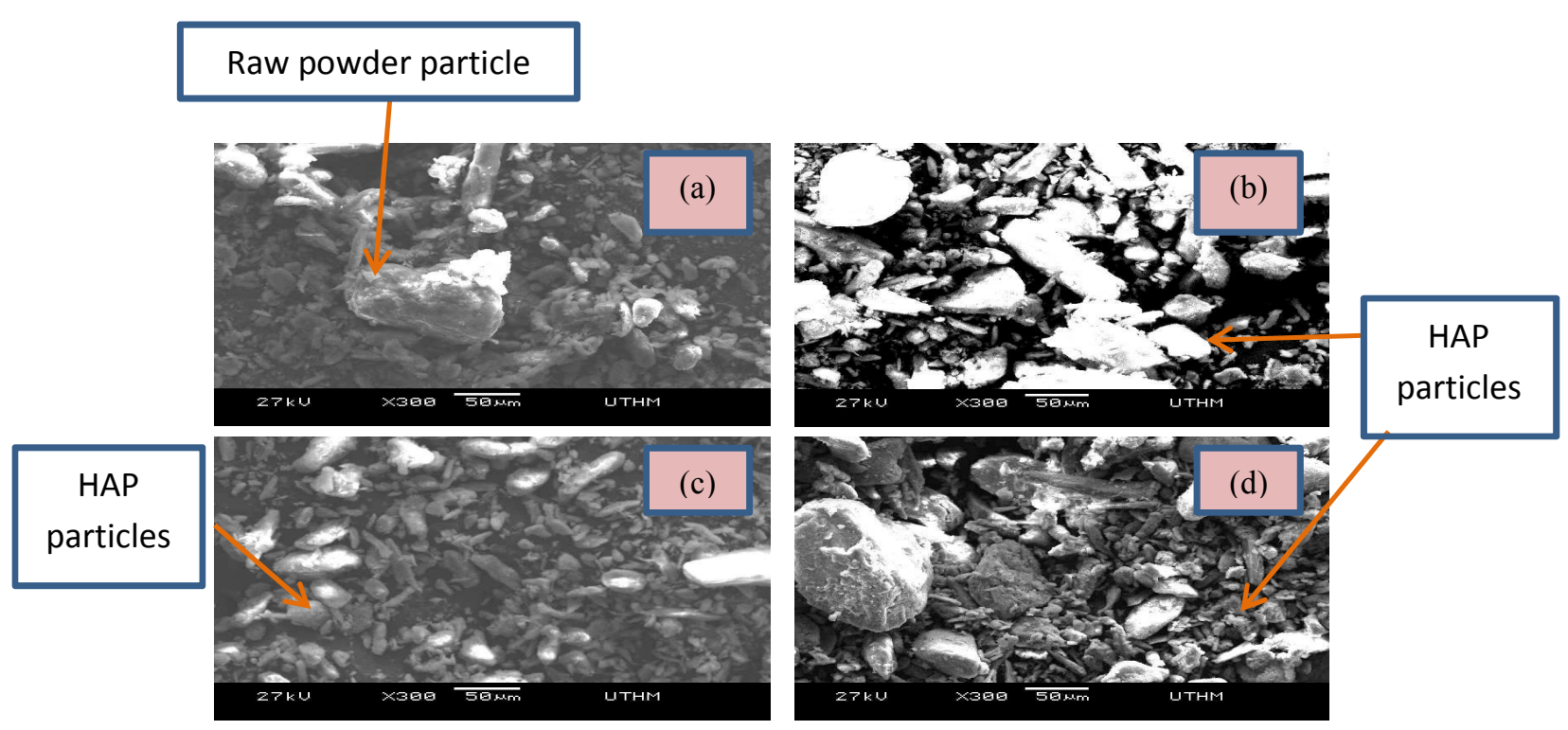

Figure 1: Microstructure of powder by SEM analysis with magnification that uses equal to X300 (a) raw powder and Calcination temperature at (b) $800{ }^{\circ} \mathrm{C}$ (c) $900{ }^{\circ} \mathrm{C}$ (d) $1000{ }^{\circ} \mathrm{C}$

Electron Dispersive Scanning Analysis. The chemical compositions of raw powder and after calcination were analyzed by using EDS analyzer. By referring the EDS result the $\mathrm{Ca} / \mathrm{P}$ ratio of the sample were calculated and the ratios are1.827 for raw powder then $1.773,1.699$ and 1.715 at temperature $800{ }^{\circ} \mathrm{C}, 900{ }^{\circ} \mathrm{C}$, and $1000{ }^{\circ} \mathrm{C}$ the ratios are equivalent with other previous study.

Table 2: Stoichiometry Ratio

\begin{tabular}{cccc}
\hline Sample & $\begin{array}{c}\text { Weight of } \\
\text { Calcium } \\
(\%)\end{array}$ & $\begin{array}{c}\text { Weight of } \\
\text { Phosphorus } \\
(\%)\end{array}$ & $\begin{array}{c}\text { Ca/P } \\
\text { Ratio }\end{array}$ \\
\hline Raw & 16.26 & 6.89 & 1.827 \\
Powder & & & \\
$\mathbf{8 0 0}^{\circ} \mathbf{C}$ & 25.79 & 11.24 & 1.773 \\
$\mathbf{9 0 0}^{\circ} \mathbf{C}$ & 21.86 & 9.94 & 1.699 \\
$\mathbf{1 0 0 0}^{\circ} \mathbf{C}$ & 31.67 & 14.27 & 1.715 \\
\hline
\end{tabular}

X-Ray Diffraction (XRD) Analysis. XRD analysis is used to confirm the purity and stability of the powder before and after calcination process. The figure bellows exhibit the XRD pattern for tilapia fish and scales that have been treated at different temperatures. The HAP crystalline composition of tilapia bones for raw powder and at $800{ }^{\circ} \mathrm{C}$ are similar with HAP pattern (JDS 00-009-0432) and the chemical reaction is $\mathrm{Ca}_{5}\left(\mathrm{PO}_{4}\right)_{3}(\mathrm{OH})$ then at temperature 900 and 1000 similar to HAP pattern (JDS 00-055-0592) with chemical reaction equal to $\mathrm{Ca}_{10}\left(\mathrm{PO}_{4}\right)_{6}(\mathrm{OH})_{2}$. The peaks of intensity were increased with the increment of calcination temperature and the decrease width [6]. This is due to removal of organic portion and substances that contains in the powder [5]. 


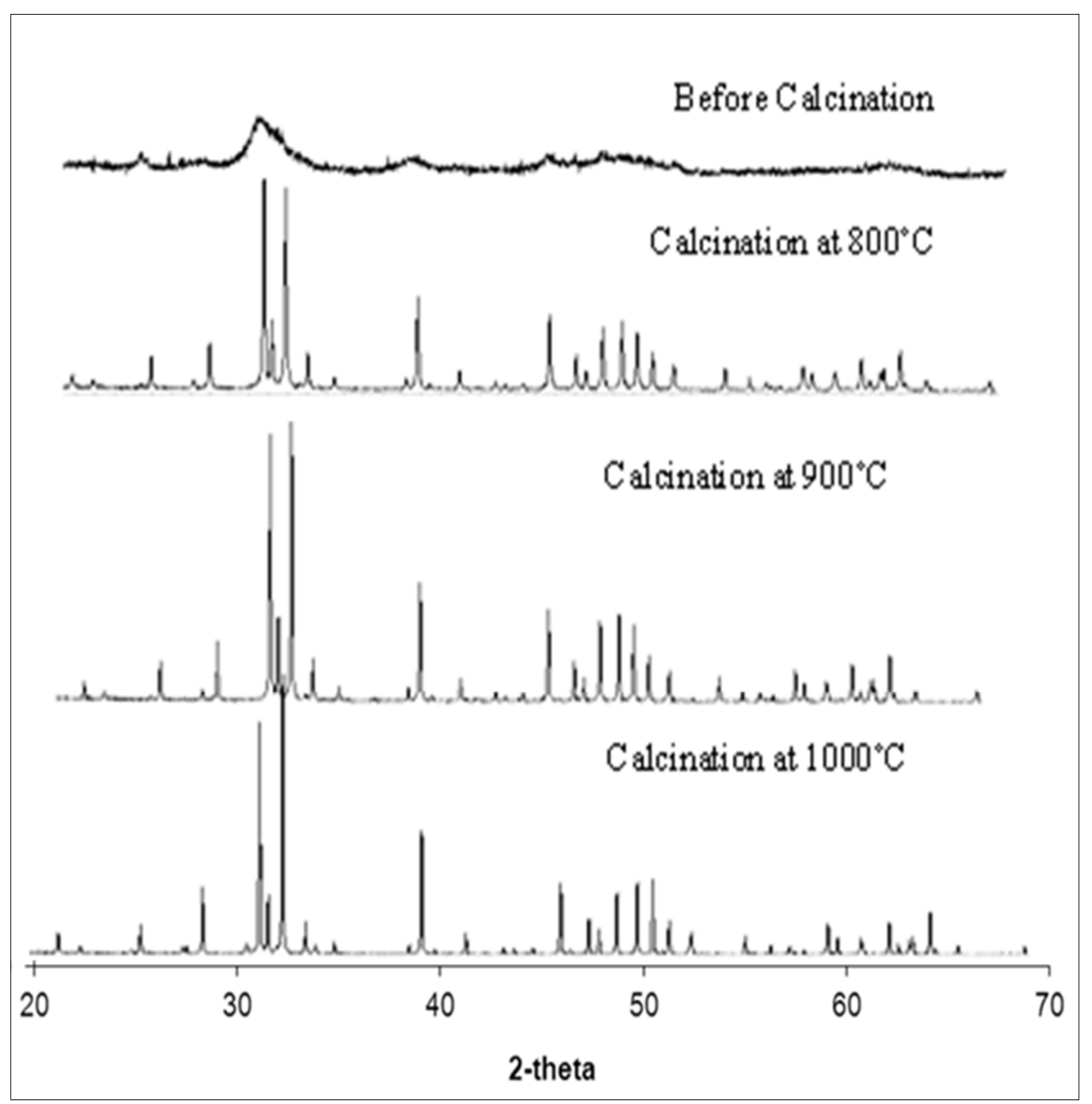

Figure 2: XRD patterns of HA powder at different temperatures

\section{Conclusions}

Calcination is a smart way in order to derive the HAP powder by ranging the temperature which was increased while observing the characterization. This is due to low cost and uncomplicated method. Based on the observation, its can conclude that the result of HAP derivation at $900{ }^{\circ} \mathrm{C}$ is 1.699 which is closely approximate to theoretical HAP stoichiometry ratio and the color of powder description is white.

\section{References}

[1] Qiang, F., Nai, Z., Wenhai, H., Deping, W., Liying, Z., and Haifeng, L, (2004). Preparation and characterization of novel bioactive bone cement: Glass based nanoscale hydroxyapatite bone cement, Materials in Medicine, 15, 1333- 1338.

[2] Alejandro Sáenz, Eric Rivera-Muñoz, Witold Brostow, and Victor M. Castaño,(1999) JournalOf Materials Education Vol.21 (5-6): 297 - 306

[3] Horng Yih Juang and Min Hsiung Hon (1996) Effect of calcination on sintering of Hydroxyapatite.Elsevier Science Limited, Biomoterial (2059-2064)

[4] M. Boutinguiza, J. Pou , R. Comesaña, F. Lusquiños , A. de Carlos , B. León (2012) Materials Science and Engineering C 32 478-486

[5] Venkatesan, J. and Kim, S.K. (2010). Effect of temperature on Isolation and characterization of Hydroxyapatite from Tuna (Thynnus obesus) Bone Materials, 3, 4761-4772

[6] R. Asmawi ${ }^{1}$, M.H.I. Ibrahim ${ }^{1}$, A. M. Amin ${ }^{1}$, Iis Sopyan (2013) Synthesis and characterization of nanocrystalline hydroxyapatite powder 